\title{
Reporting on timber decay in a condition survey
}

Received (in revised form): 26th July, 2004

\begin{abstract}
Ronald Wilde FRICS, FCIArb, FAE
is a chartered building surveyor and consultant to the building surveying practice of Wilde Spooner Raleigh. For some years in the late 1950 s and 1960 s he was a director of a leading company in the field of timber treatment and, after returning to professional practice, he continued to specialise in this field as well as working in the general field of building surveying in private practice. He has been consulted concerning problems of timber decay in many historic and other buildings. He is a fellow of the Academy of Experts and has acted as an expert in many cases in the courts where the action concerned either contractual disputes or claims against surveyors. He is a practising arbitrator and has arbitrated on a number of disputes concerning timber decay.
\end{abstract}

\begin{abstract}
The objective of this paper is to help surveyors reduce the risks posed by hidden dry rot in buildings surveyed. This paper discusses some of the problems of reporting on the presence, or risk of, concealed fungal decay (including dry rot) when making a condition survey of a property. It stresses the need for a diagnostic approach to the inspection and gives examples of how the courts have approached cases where it is claimed that the surveyor failed to discover dry rot and/or warn of the hidden risk of undiscovered rot in buildings.
\end{abstract}

\section{Keywords:}

dry rot, dampness, diagnostic approach, assessing hidden risk, reporting

\section{INTRODUCTION}

Surveyors are understandably upset when it is found that they missed dry rot or other forms of timber decay in a building where they have made a condition survey. When this turns out to be in timber that they could not have seen, given the limitations of the inspection (limitations that were set out clearly in the report), it is natural for the surveyor to feel that this really was just a matter of bad luck. It is sometimes said that some people make their own luck and this paper tries to see how far this can be achieved in such cases.

Of course, if surveyors fail to see the signs of decay in timbers which could have been examined without opening up, they will have some difficulty in defending themselves; everybody has 'off days' from time to time, but this is not a fruitful line of defence.

Ronald Wilde

Consultant to Wilde Spooner Raleigh Chartered Building Surveyors 10 Hither Acre Ilminster, Somerset TA19 9DA, UK

Tel: +44 (0) 1460259264

Fax: +44 (o) 146052180

E-mail: ronaldwilde@fsmail.net

\section{HOW THE COURTS SEE THE PROBLEM}

The most difficult problems concern either rot which was already in hidden timbers at the time of the survey but was only found later, or rot that only developed later but which was associated with dampness that could have been found (or if it had been found, about which no warning of the possible development of decay was given). In too many such cases 
Dry rot

Wet rot the courts have found that, although the rot would not have been seen in exposed places, there were signs that pointed to a significant risk of rot in hidden timbers but the surveyor failed to give the appropriate warning and advice. The courts tend to trace back from the discovered rot to try to assess what signs would have been available to the surveyor at the time of the inspection. Although the surveyor may argue that the claimant's case is made with a large measure of hindsight, too often the courts have found that there was a lack of care. So, how can surveyors change their luck?

\section{SOME FACTS ABOUT FUNGAL DECAY OF TIMBER}

The surveyor does not need to be a mycologist to report on the presence or risk of timber decay in a building, but a knowledge of some basic facts is necessary. It is not the purpose of this paper to be a treatise on the decay of timber but it may help to summarise some of the salient points.

Unlike green plants, fungi cannot make their own nourishment by photosynthesis but, instead, live off other dead plant or animal organisms (saprophytes) or living ones (parasites). Both kinds attack timber but it is the saprophytes that attack the timber used in buildings. Wood-rotting fungi grow from the germination of a spore in the right conditions. As spores are produced in astronomical numbers by the fungus and as these are so incredibly small that they are airborne and widely distributed in the air, it is probable that most timbers in most buildings for most of the time have some spores on them.

There are a number of different wood-rotting fungi which are found in buildings. These are divided into two main groups, brown rots which destroy the cellulose (one of the main constituents of wood) leaving the darker lignin (the other main constituent), and white rots which destroy both cellulose and lignin making the wood lighter in colour. The term $d r y$ rot is nowadays reserved for the brown rot, Serpula lacrymans. The term wet rot is generally applied to any other wood-rotting fungus found in buildings, whether it is brown or white.

Although the wet rots are possibly responsible for at least as much economic damage to buildings as dry rot, it is the latter which is most feared by building owners - it must be admitted, with good reason. Therefore, it is important for surveyors to try to identify whether any fungal decay is caused by the dry rot fungus and, to do this, they must know the main characteristics of the fungus and how these differ from those of wet rots.

This paper can only describe briefly the forms that dry rot can take, but there is much published material available. As a minimum, every surveyor making condition surveys of buildings should be familiar with Building Research Establishment (BRE) Digest 299 (1993) Dry Rot: Its Recognition and Control and Digest 345 (1989) Wet Rots: Recognition and Control. By far the most useful and informative publication for surveyors in the field, however, is Recognising Wood Rot and Insect Damage in Buildings (Bravery et al. 2003), the authors of which are all scientists at the BRE. This book lists all the common wood-rotting fungi 


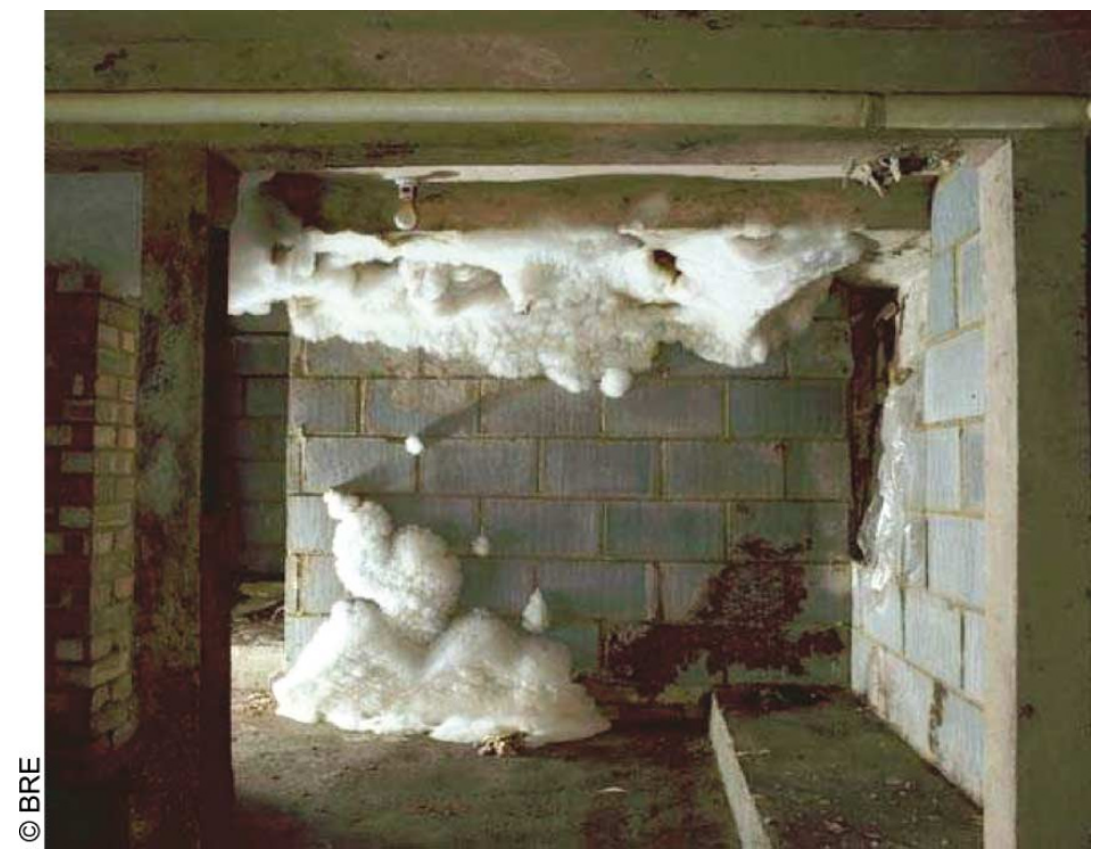

Figure 1: Mycelium of the dry rot fungus (Serpula lacrymans) in the form of fluffy cotton wool like growth

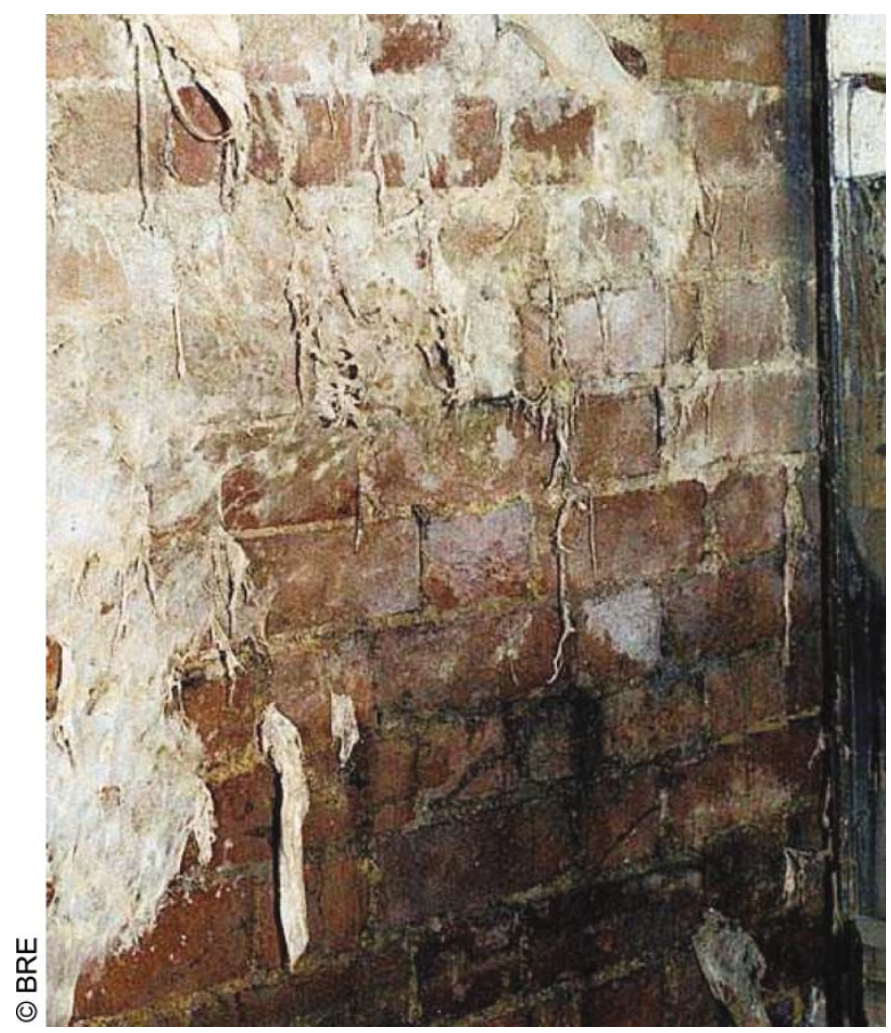

Figure 2: Mycelium of dry rot in its sheet and strand form 
and wood-boring insects with coloured illustrations and comprehensive identification charts.

The mycelium of the fungus can take one or more of three main forms, fluffy white 'cotton wool', strands or sheets. The colour of the mycelium ranges from nearly white to a rather dirty parchment colour. Fresh mycelium is often tinged with lilac or yellow. These various forms are shown in Figures 1 and 2.

The sporophore (fruiting body) of dry rot, with its rusty red centre (caused by the masses of spores) and an off-white margin, cannot easily be mistaken for anything else (see Figure 3). By contrast, the mycelium of the wet rot fungus, Coniophora puteana, is often absent except on the timber itself. It is in the form of strands which are cream colour when first formed but quickly turn dark brown (shown in Figure 4). When it is present off the timber it tends to take a fern-like form as shown in the lower part of Figure 3.

As the BRE book points out, from the point of view of the condition survey, it is not necessary to distinguish between the many species of wet rot as the same treatment is necessary for all of them. (This is not to suggest that it is less important to have identified wet rot in a building; I have seen whole modern blocks of flats where every window had to be replaced because of wet rot.)

\section{LOOKING FOR EVIDENCE OF DECAY IN EXPOSED TIMBERS}

Except for the formation of sporophores in well-established attacks which can develop in exposed places (even on the outside face of external walls), it is not very common for the mycelium of wood-rotting fungi to be found on any of the timber faces or other surfaces accessible for inspection without opening up; what the surveyor has to look for is the effects that such fungi have on the timbers that can be seen.

In the case of both dry rot and cellar fungus, an attack causes the wood to crack both along and across the grain, forming cubical cracking in a wellknown way. In its earlier stages of development, however, this cracking does not extend to the exposed surface of the timber but, as the timber behind has lost substance, the surface shrivels and produces a characteristic waviness. Figure 6 shows a board with such a veneer of sound wood. A good example of this problem is shown in the timber in Figure 5.

Just to confuse matters, however, sometimes the lost cellulose is replaced by water so that there is no visible distortion of the timber. The characteristic of such timber is that, when probed with a knife, it will not grip the blade as would sound wood and the texture is rather like cheese.

All this means that decay in timbers which are partly exposed may not be determined by sight alone. The knife will also help the surveyor to determine incipient decay. If it is possible to prise off a splint from the surface of a piece of timber and it breaks off short, there is (or has been) some decay. Also, in the case of softwood, no matter how ancient the timber is, the splint will have a resinous smell which will be absent if the wood is decayed, even without cubing or other determinable loss of substance. A word of warning here, however, only millimetres away from 
a positive smell test the same piece of wood may have no resinous smell and be subject to attack.

There is a problem with identifying timber decay from the appearance of attacked timber alone which is summarised in BRE Digest 299 (1993) which states: '. . the appearance of the damaged wood cannot in itself be used in recognition, because dry rot infected timber can resemble very closely timber that has been damaged by wet rot fungi'. Because of the problem of access to hidden parts, it is probable that the only direct evidence of decayed timber that a surveyor will find is in timbers which are exposed and accessible for inspection. Clearly, it is insufficient to report only on these. So, how can surveyors cope with this problem and also deal with the risk that the timbers (or parts of them) they cannot see may be attacked and, if so, determine what kind of attack it is likely to be?

\section{REPORTING ON RISK}

The key is locating and recording the observable facts and then assessing and advising on risk. In the field of purchase of property, every thinking prospective owner knows that buying a building presents a risk. Most of them feel that they do not have the skill to recognise problems and the more prudent of them rely on a surveyor's expertise to supply that know-how.

Surveyors, however, probably know better than the client the nature of the hidden risk in that significant parts of the building will remain hidden; even on the rare occasions when the surveyor is given permission to carry out extensive opening up, every hidden problem still may not be found (and how rarely indeed is such permission given anyway?). Reducing this risk is fundamental to making condition surveys of buildings. An important aspect of this is that surveyors have to do more than just record bare facts, they have to indicate the significance of what can be

The diagnostic approach deduced from these. In other words, there has to be a diagnostic approach.

In the matter of using diagnostic skills, there is a close parallel between surveying and medicine. Consider what a doctor does when people go to a surgery with worries about their health. Much of what can go wrong lies below the skin and the doctor has to make an initial diagnosis based on external signs coupled, possibly, with very limited internal examination. Often, these external signs, although of no significance to the patient, give a clear indication of what might be wrong. Once the doctor has made a diagnosis he may be certain of what is wrong and will advise accordingly. In other cases he may advise tests, ranging from taking blood samples to exploratory surgery.

In some ways, the task facing the surveyor is more difficult than that of the doctor. At least patients usually go to the doctor with something that has caused them concern; in the case of surveys, the client often has no particular worry and so there is nothing in the instructions to point to a particular risk. Also, the building cannot be asked to tell where it hurts! While all aspects of the condition survey have to be approached in a diagnostic way, this is particularly important in the case of dry rot and the risk of dry rot.

Traditional buildings contain a substantial amount of timber. Surveyors making a condition survey of such a building have two problems. The first is that, without opening up, some part of virtually 


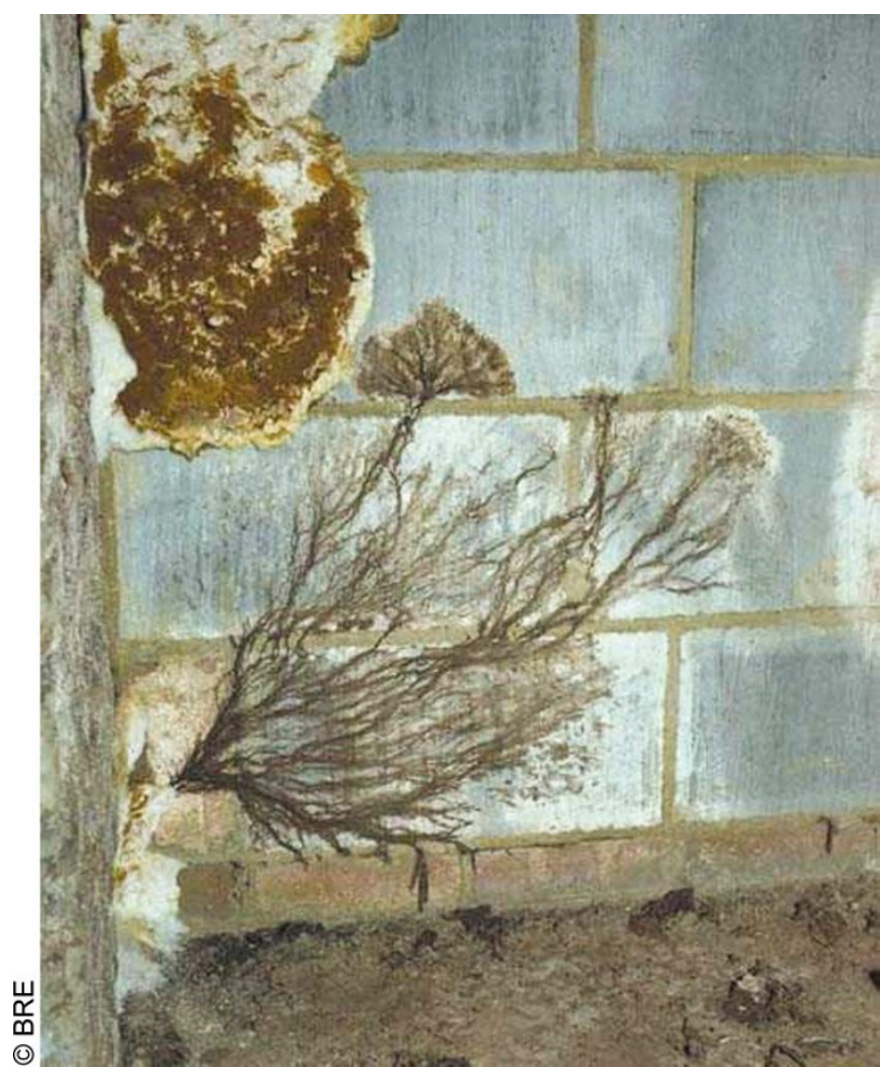

Figure 3: At the top is a sporophore of dry rot, Below it are the strands of the wet rot 'cellar fungus' (Coneophora puteana)

\section{The hidden timbers}

all of the timbers will be concealed from view, including the backs of much of the joinery, such as skirtings and window frames, the underside of floorboards and the bearing ends of rafters. Many timbers, such as floor joists, wall plates, the battens and laths supporting the wall plaster and the so-called bonding timbers of many historic buildings, are totally concealed. Even after the limited opening up which

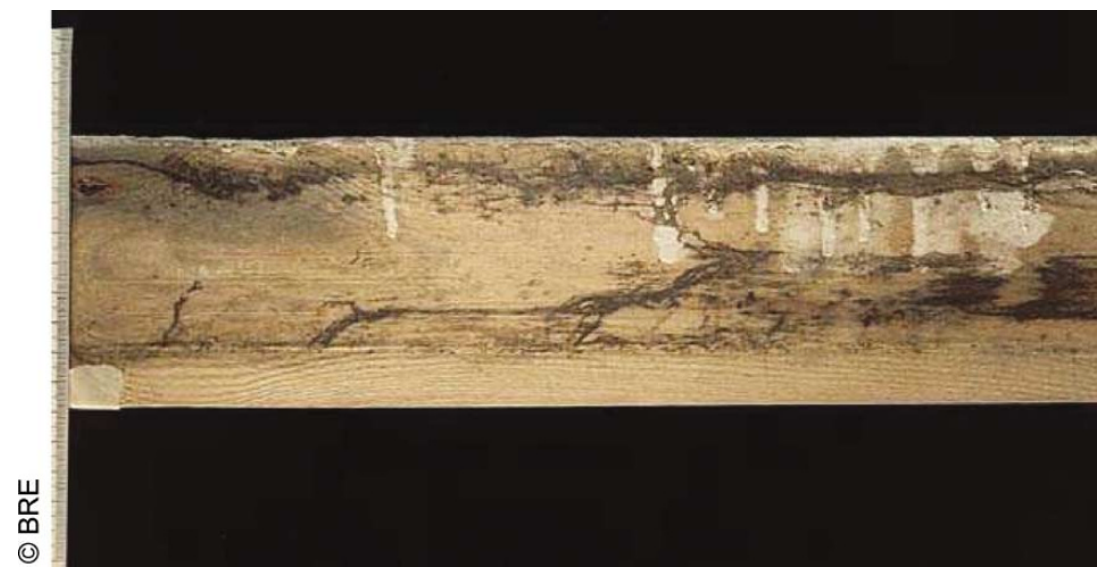

Figure 4: This shows the mycelium of the cellular fungus growing on timber 


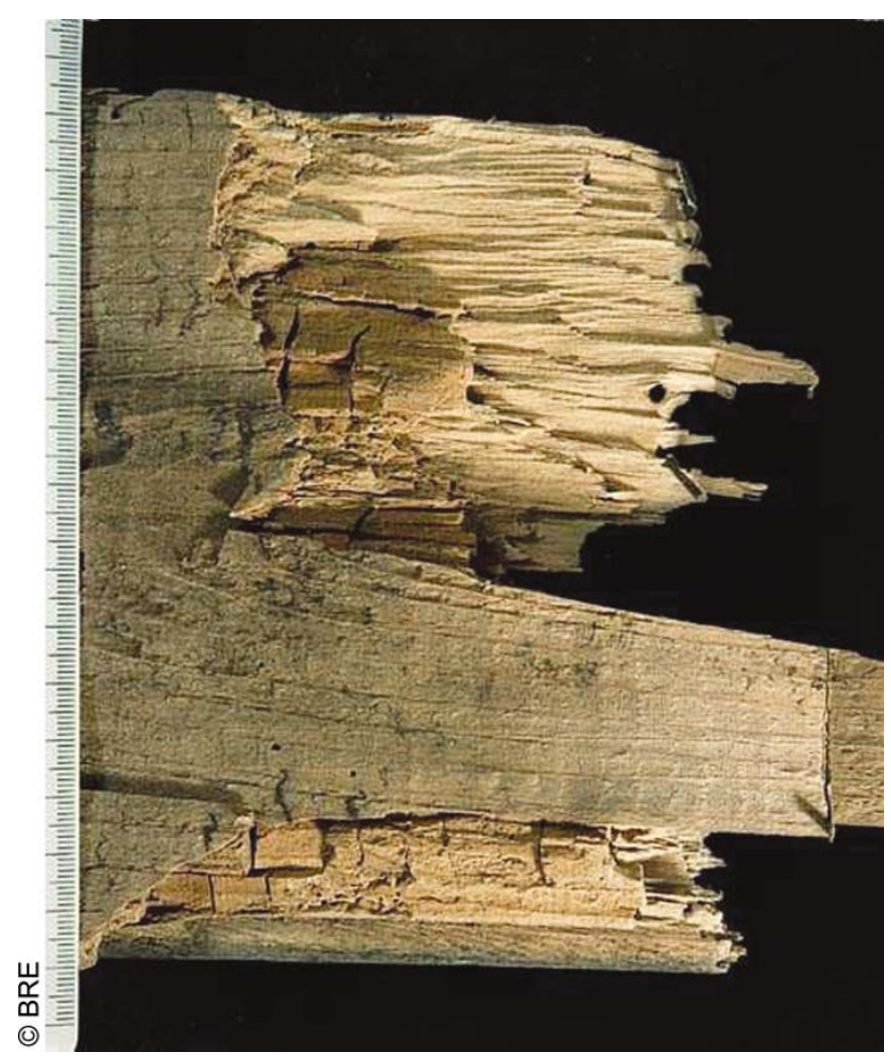

Figure 5: A board attacked by dry rot where the surface of the timber remained unbroken by the fungus

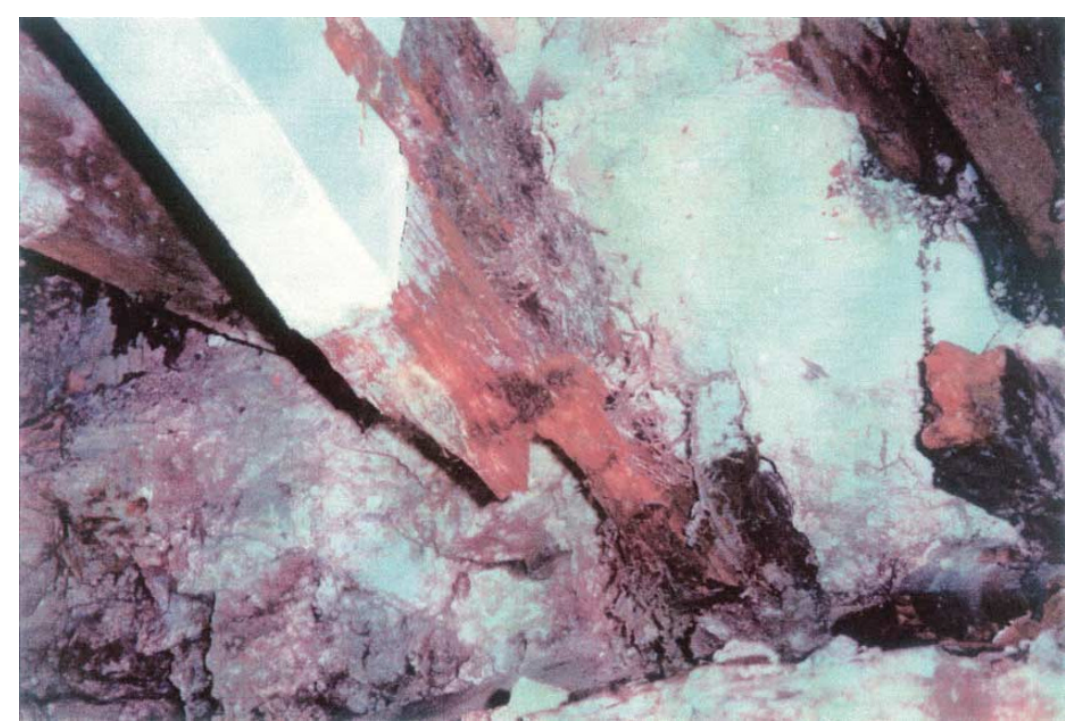

Figure 6: A timber which had decay only in the concealed part before opening up

may be possible on a survey, many timbers - the bearing ends of floor joists, the wall plates and the sole of lead-lined gutters, for example will remain hidden. Even the timbers which are not concealed by the way the building is constructed may be obscured by floor coverings, furniture and effects. 


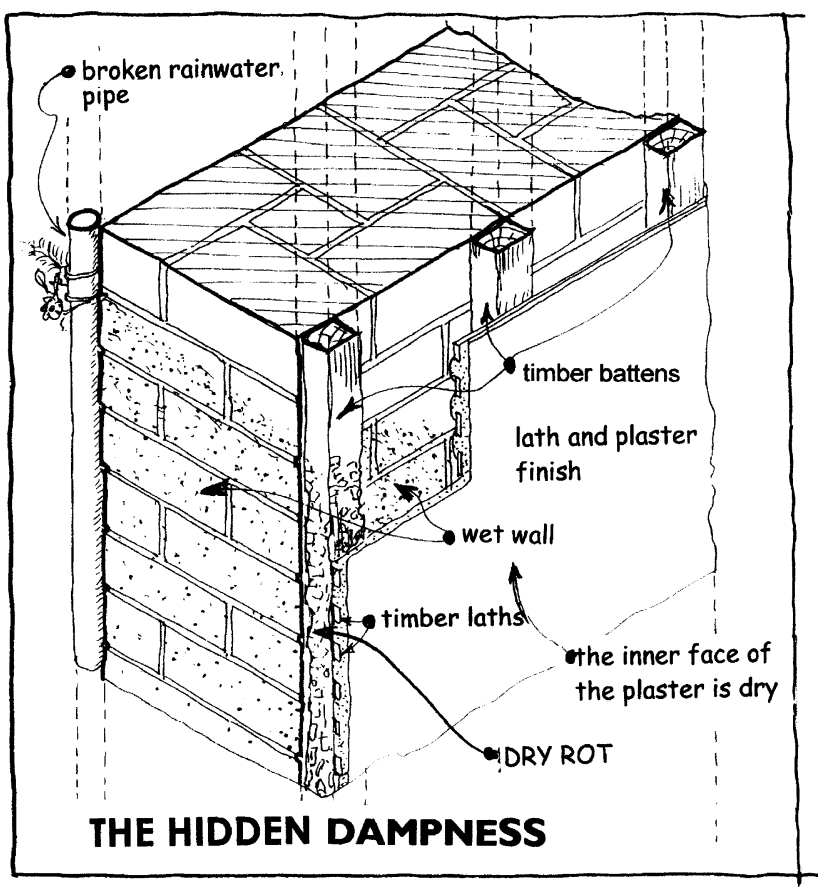

Figure 7: Hidden dampness

Figure 7 also shows a common location for hidden dry rot. The dry rot at Figure 2 was in such a location.

The second problem is that, as fungal decay is caused by one or other living organism, a few months after a survey is made a totally hidden attack may have spread to become painfully obvious to even the least observant ex-client.

There is one further point on reporting where care is required. In a case of which I have heard, a surveyor reported on an external rainwater pipe that was obviously leaking with staining on the brickwork. He reported properly that this pipe should be repaired or replaced and added words to the effect that if this was not done there was a risk of dry rot. The clients bought the house and, as soon as practicable, renewed the pipe. Notwithstanding this prompt action, dry rot was subsequently discovered in timbers immediately behind the pipe and a claim was made against the surveyor. Here the surveyor failed to realise that there could have been concealed dry rot in timbers in the wall behind the pipe or, even if it was not there at that time, that the brickwork could have remained wet for a sufficient time for a fresh attack to develop even after the pipe had been renewed.

\section{DAMPNESS IS THE KEY}

Certain conditions are necessary for the fungus to germinate and for it to grow. These include a moderate temperature, the presence of oxygen, some timber (or material made from timber) and moisture above about 20 per cent of the dry weight of the timber. All of these, except the last, exist in almost all habitable buildings, but properly designed and maintained 
buildings are too dry for the rot to develop and thrive (the prevention of timber decay is a major reason for them to be designed in that way).

When the timber in a building has a moisture content of over 20 per cent it is able to support dry rot (although it needs a considerably higher level for an attack to start). Occasional spillage of water causes little risk, what is dangerous is timber being kept persistently damp.

Two facts about traditional building construction in combination are very relevant to this risk. The first is that solid masonry, and particularly brickwork, is very porous and, if wetted, can hold large amounts of water which it will give up only slowly, even when positive steps are taken to dry out the structure. The second is that a considerable amount of the timber in a building is in intimate contact with the masonry-it is either built into the brickwork to take its bearing (wall plates and joist ends) or is built against the brickwork (skirtings and door and window frames). The moisture content of timber in such intimate contact will quickly come into equilibrium with the wall, if the wall is wet the timber in contact is very likely to be wet enough to be attacked by dry rot and/or other wood-rotting fungi. There is a very real risk that timbers that are vulnerable, in fact, will be attacked.

\section{WHERE IS THE BUILDING WET?}

It is obvious that the key to advising on the risk of hidden dry rot is to locate the areas of persistent dampness. Of course, surveyors always have looked for visual evidence of dampness such as staining, but the tool of choice for modern surveyors is the electronic moisture meter which will record dampness, even where there is no visible sign of it.

On most surveys, however, it is impractical to cover the whole building, both horizontally and vertically, with systematic readings on a close grid. When the evidence is considered after a claim is made and it is established that the dampness (and therefore the risk of concealed timber decay) could have been found if only a moisture test had been made in a particular

\section{Problems of locating and recording dampness}

place, surveyors have a real problem if they cannot recall exactly where they took their moisture readings and demonstrate that their choice of location was reasonable.

There has been a case in the Official Referee's Court ${ }^{1}$ (the precursor of the Construction and Technology Court) where a surveyor had taken systematic moisture readings but had not recorded where these were taken, nor could he remember, many months later, what precisely he had done. It was accepted by the court that he had made moisture tests with a meter but he was found to be negligent for failing to take a reading in the actual place where this would have revealed a problem.

A word of warning should be given here: there are often timbers that may be wet enough to support dry rot but which cannot be reached to test with a meter. Many very old and important buildings have their external walls faced internally with lath and plaster on timber battens. Even severe dampness in the brickwork may not show or be recorded on a meter on the inner face, yet there can be horrendous dry rot on the concealed battens and laths. This condition is illustrated, diagrammatically, in Figure 7. 
Even when the inner face of a thick wall is dry this does not mean that the core of the wall is free from dampness. For example, if there are heavy roof trusses or substantial floor beams embedded in the wall the hidden parts may be seriously attacked. There are ways in which such timbers may be inspected but these are rarely possible on a pre-purchase condition survey. Here the surveyor has to assess the risk from whatever evidence there is of past or present dampness and advise accordingly.

To look on the bright side, if it can be shown that there could have been no indication of dampness in accessible places, even with the use of a moisture meter or assessment of other visible indications, then there would be a good defence to the claim. For example, there was an outbreak of dry rot in my experience where it was found that there was a pinhole leak in the rising water main running under the suspended timber floor of a house. This was producing a fine but constant spray to the underside of the floor. There were fitted floor coverings above to obscure any signs of dampness. This was causing a vigorous dry rot attack in the floor. Had a claim been made against a surveyor for failing to put this dampness on notice there would have been a good defence. Of course, if the floor gave evidence of loss of structural support this would have been a different matter, as discussed later in this paper.

As part of the condition survey, surveyors will have looked for signs of wetting of the structure and will have been aware that unwanted water in a building comes from four main sources: water falling on the outside of the building from rain or snow and finding a route to reach the timber; water from the ground, rising through porous masonry by the process of capillarity; water which has leaked from plumbing both inside and outside of the building; and water which has condensed from the air.

\section{WHERE DO THE GREATEST RISKS LIE?}

The signs of such failures are not always obvious on the inside of the building and, in some cases, such as when the wall plaster is battened off the wall, the dampness cannot be found easily, even with a moisture meter. Although the outside of the building will be examined systematically for signs of dampness, it is helpful to be aware of those parts of a building which experience has shown are particularly vulnerable so that routine examination can be supplemented by closer examination of those areas.

Perhaps the commonest situation is leaks and blockages of external

Behind external pipes

\section{Parapets} pipework, and staining on brickwork starting behind a joint in a rainwater pipe is always a cause for concern. Sometimes it is not easy to see the wall surface behind the conglomeration of pipes which often occur in the angle between the main back wall and the back addition of many older town houses, but it is sufficiently common for dry rot to occur in this location to suggest that surveyors should be particularly cautious here. A detailed examination of skirtings and window frames here is also a good idea.

Parapets and parapet gutters are a fruitful cause of dry rot. Not only are the parapet walls themselves exposed on both faces, the coping stones are often poorly pointed with no damp-proof course (DPC) under them. 


\section{Parapet gutters}

\section{Timber-framed buildings}

This combination can make the masonry of the parapet wet and put the structural timbers below at risk of decay.

Even more of a problem in this location is badly designed and split lead linings to parapet gutters (such faults are far too common). A problem with dry rot in this location is that it can occur without any of the telltale signs of internal dampness to assist in its identification. The decay is sometimes confined to those parts of the timbers which are totally embedded and, even if there is some decay in the exposed part that could be reached, this calls for very difficult 'hands on' inspection because of the very restricted headroom.

In a case in $1998^{2}$ a surveyor had reported on a Georgian mansion where there was an external cornice with a parapet wall above and a leadlined gutter behind. There were various faults in these but, because there were attic rooms within the profile of the roof, most of the roof timbers could not be examined. There was a small void over the projecting front entrance, but access to this void was difficult and the headroom was low. This void was accessible, however, and had it been carefully examined, this would have shown some signs of dry rot in timbers under the parapet in that location, which, if found, would have signalled to the surveyor that there was a strong risk that other timbers below the parapet were equally vulnerable. Subsequent opening up as part of a scheme of refurbishment by the new owners disclosed very extensive dry rot at a high level in this building. The surveyor was found not to have acted with due care and substantial damages were awarded against him. The lesson from this is that the external evidence of potential problems make it particularly important to explore every opportunity to resolve the doubts and, where these doubts cannot be resolved, to report on the risk.

Traditional timber-framed buildings present their own special problems. Even when such durable timber as oak is used, decay, following centuries of contact with the ground, is evidenced by the number of buildings where the sole plates have been replaced with brickwork. If this has not already been done it would be prudent to arrange for inspection of at least part of the bearing surface. Of the timbers above ground level in such buildings, the greatest problem for surveyors occurs where there is external rendering concealing the frame. Experience shows that probably the most vulnerable timbers above ground are the corner posts, although all timbers are vulnerable.

Often the surveyor is denied the evidence of distortion due to loss of support because the load which should be carried by the main structural timbers is transferred to secondary timbers and even to the brick infill panels. In these traditional timber-framed buildings the attacks are most commonly (but not exclusively) by a wet rot fungus, very frequently associated with an infestation by the deathwatch beetle.

Another location where dry rot is not uncommon is below showers installed on an upper floor. If the pointing between the wall and the shower tray fails, ideal conditions for decay are formed. In older buildings the floors may not be sufficiently rigid to avoid such cracks forming.

One of the commonest sources of internal dampness in buildings is water that has risen from the ground and this is, perhaps, the commonest 
cause of wet rot in buildings. Surprisingly, it is my experience that this is not a common cause of dry rot unless there was some additional source of dampness (although the rising damp alone will sustain an attack that has already been started by another source of water).

Condensation is often responsible for serious damage to suspended flooring on the ground floor, although this is nearly always caused by wet rot. All surveyors are aware of the need for sub-floor ventilation with a through draught where the floor is above an oversite that has no vapourproof membrane, although it is doubtful whether most voids are sufficiently well ventilated to deal with a particularly wet oversite even if the airbricks are set opposed to each other and there are no obstructions such as solid floors or walls. The fact that a terracotta airbrick has an open area of only about 6 per cent of its face and the holes are likely to be clogged with cobwebs and dirt means that much of such ventilation lies in the realm of wishful thinking.

On the other hand, many buildings with an apparently inadequate disposition and size of airbricks do not have a problem because the oversite is naturally dry. What the surveyor has to do is to try to establish the actual conditions as they exist.

\section{DAMPNESS IS NOT THE ONLY KEY TO HIDDEN DRY ROT}

Even if surveyors have noted and discussed every source of dampness they still may be vulnerable to a claim for missing dry rot if they fail to associate signs of structural weakness with loss of strength of timber due to decay.

In a case in my experience, ${ }^{3}$ a wall above a ground-storey bay showed signs of some structural movement which subsequent investigation showed to have been caused by dry rot in the bearing end of the heavy timber bressummer supporting the wall over the opening for the bay.

There was no visible sign of dampness or a likely cause of such (a porch roof near to the bearing end had recently been re-tiled and, with hindsight, the cause of the dry rot was found to be the previous condition of the flashings to that roof). It was not suggested that the surveyor should have known about the past dampness and it was argued on the surveyor's behalf that there were a number of possible explanations for the distress in the wall. The judge asked the expert giving evidence on the surveyor's behalf 'couldn't the cause also have been dry rot?', to which the answer had to be 'yes'. The surveyor was found, in that instance, to have failed in his duty of care because he did not advise the client of this possibility.

So, surveyors have to ask themselves in every case of structural distortion or springiness in floors 'could this be because some structural timber is now inadequate for its purpose?'. Sometimes, of course, this is because the timbers are now overloaded, as when slates on a roof have been replaced with heavier concrete tiles or major timbers have been cut through in ignorance, but a possibility may be that some structural timber has been weakened by fungal decay. The judge's question quoted above should always be remembered, even when the surveyor is (rightly) satisfied there is no dampness in the area at the time of the initial inspection. 


\section{Assessing risk}

\section{Summarising reports}

A claim will not be defeated necessarily by a defence that the attack is dead, if the building has been damaged by dry rot so that structural repairs are necessary, the surveyor has a duty to advise on the condition and to assess the cause.

\section{REPORTING}

Surveyors do their best to assess the risk to those parts of a building that they cannot see, but even so, they can be in difficulty if they fail to convey their concerns to the client in unequivocal terms. First, in writing the report, surveyors must treat pro-forma reports and standard paragraphs with caution. The danger is the tendency to try to fit the facts to the closest standard paragraphs rather than the other way around. When trying to convey a perceived risk, surveyors have to bring original thought to each and every case. Sometimes it is difficult to convey the message in a few words.

It is a risky business to own a property, as far as possible surveyors have to identify the risks, but it is for the client to take the risk, not the surveyor. The client, however, can only take the risk if they fully understand it. Although surveyors have to try to be as concise as possible, they must be sure that they put in the report everything that is necessary for the client to understand the risks that they are accepting.

One thing that surveyors have to guard against is having a gut feeling that, although there is a theoretical risk, it is likely that there is no problem. What they should not do is fail to give a warning. If they feel strongly about it they could say something like "while it is by no means certain that my fears are well founded, they can only be resolved by further investigation'. It should be remembered that even if it is thought that there is only a 1-in-50 chance of the worst case prevailing there is also a 1-in-50 chance of the surveyor being found negligent if the risk is not mentioned. By the time surveyors have carried out 50 surveys their risks are dramatically increased.

Great care also has to be taken if surveyors summarise their findings at the end of their reports. I was told of a case which was heard many years ago, although I do not know its name. Here a surveyor found and reported on a number of serious defects in a building. He also saw a very small amount of timber decay in a skirting on the half landing on the stairs. He properly advised that this should be investigated but clearly this decay did not loom large in his mind and when he came to summarise his findings at the end of his report he only described those serious defects that had concerned him.

Unfortunately, it turned out that, in fact, there was very serious and extensive dry rot in the building of which the rot in the skirting was the only visible manifestation. This rot was only discovered after the purchase of the property. The client argued that, as the rot was not summarised at the end of the report, it was assumed that the surveyor did not consider it to be serious and so the client had not investigated it before purchase. The court supported him and found that the surveyor had acted without due care.

Finally, it is important to choose one's words carefully. It is unscientific to make a positive identification on limited evidence. For example, in one case a careful surveyor managed to find some evidence of decay in a piece 
of timber but did not have sufficient evidence to identify what species of fungus it was. This surveyor therefore reported only that there was evidence of fungal decay and that this should be investigated. The attack was subsequently found to be dry rot but only after the house was bought. The client made a claim, saying that she was not worried about fungal decay in timber and, therefore, had not thought it necessary to investigate, but she was very scared of dry rot and would have done more had she known that this was a risk! The surveyor should have said that the attack was fungal decay that, possibly, could be dry rot.

This paper does not deal with the detailed work of full investigation of decay in buildings or putting in hand the necessary repairs. It is important that the surveyor making a condition survey tries to advise on the possible magnitude and cost of repair. (This is notoriously difficult and measuring a piece of string comes to mind.)

It is now well recognised that dry rot and other wood-rotting fungi will stop growing when the conditions for their growth are removed, and when there is insufficient moisture to support an attack the fungus will stop growing and then die. There is therefore a belief that, perhaps, dry rot in buildings is not such a serious matter as was once thought. It is true that massive irrigation of walls and extensive cutting away of timber beyond the last sign of attack is not now considered necessary or desirable but a substantial part of the cost of dealing with any dry rot attack has always been in the work of opening up for inspection, the replacement of damaged timber, the isolation of timber from walls still wet and the work in removing the cause of dampness. All such works are necessary in dealing with every dry rot attack. As BRE Digest 299 (1993) indicates, it takes time to make a wet building dry and it may be necessary to undertake some chemical treatment to buy that time.

Long experience has persuaded me that any assessment of the final cost of treatment and repair at the time of the first discovery can be so wide of the mark that giving firm advice on this cost before the full extent of the attack is known is a dangerous matter; too low an estimate is an invitation to be sued and too high may lose the client his purchase. The advice has to be that the client should try to persuade the vendor to allow proper investigation and that, failing this, the client could face substantial unknown costs.

\section{ADVISING ON FURTHER INVESTIGATION}

In every aspect of building, as in medicine, there are specialists with greater skill and experience than the general practitioner and it is necessary to know when to advise a client to seek help and, if so, from whom to seek it. Building surveyors, by their training and experience, should be able to arrange and carry out detailed inspection including opening up, specifying the works, supervising the repair and replacement of damaged timbers and any necessary treatment. The difficulty will be when, as is likely, the client asks for a guarantee. Of course, building surveyors will not be insured to provide this and, even if they were, most would be unlikely to take on the liability. The treatment companies, of course, will be very willing to give such a guarantee but only if they do the work in accordance with their own specification. This may involve much more work than the building 
surveyor considers necessary. Some specialist companies, however, do adopt much more of a conservation approach and these should be sought out. In any case, it is only during the period when the building is drying out that the guarantee is of any value; all of the long-term guarantees that I have seen are qualified by the proviso that they are only valid as long as the property is maintained in a dry condition. If it is so maintained, however, then there will be no recurrence of the dry rot anyway, whether the guarantee is for 10,30 or 100 years and, if it is not so maintained, a claim on the guarantor is likely to fail.

What surveyors cannot do is abdicate their responsibility to make the initial investigation and to report on the presence (or risk) of fungal attack on timber. A specialist company making an initial survey will have exactly the same limitations as the surveyor making the condition survey.

\section{TO SUM UP}

What should surveyors do to reduce the risk of not advising properly on the presence or risk of timber decay in buildings?

- First, they must make as detailed an inspection as possible to determine where the building is damp and, based on this, make an assessment of the probable dampness in hidden parts. They then must use this assessment to determine which timbers are at risk.

- In the case of visible timbers they must diligently look for signs of attack, note all signs of distortion in the structure and consider whether this could be an indication of decay.

- They must pay particular attention to timbers that have, or might have, a moisture content of over 20 per cent of the dry weight of the timber, remembering that timber will come to equilibrium with the moisture content of the walls.

- They must examine all visible timbers for signs of attack, including using a knife or spike to test the substance of the timber, note all structural distortion and assess the possibility that the distress may be due to past or present decay of timber.

- They must make sure that all established facts are recorded and that the client is made aware of all perceived risks. Insofar as (in an attempt to be concise) the report does not show all of the reasoning for giving a particular piece of advice, it is most important that the surveyor's notes are retained in a permanent form and, if the report was dictated on site, special notes should be made.

- Finally, they must indicate what further investigation is required to resolve doubts and, most importantly, make clear the risk of not doing so before entering into a commitment to purchase the property.

(C) Ronald Wilde 2005

\section{References}

Bravery, A.F., Berry, R.W., Carey, J.K., Cooper, D.E. (2003) Recognising Wood Rot and Insect Damage in Buildings, 3rd edn, Building Research Establishment, Watford. 
Building Research Establishment Digest 299 (1993) Dry Rot: Its Recognition and Control, BRE, Watford.

Building Research Establishment Digest 345 (1989) Wet Rots: Recognition and Control, BRE, Watford.

\section{Notes}

(1) Fryer and Another $v$ Bunney \& Taylor [1981] High Court QBD Official Referee's Court (reported in Structural Survey).

(2) Republic International Trust Company Limited $v$ Fletcher Ramos \& Co [1998] QBD (T\&CC).

(3) Poulton $v$ Ibitt Mosely and Card [late 1970s] QBD Official Referee's Court. 